\title{
Patrón de acumulación neoliberal entre Estados Unidos y México desde la óptica de José Valenzuela Feijóo
}

\section{Oscar Mañán*}

Tengo el privilegio de comentar aquí un trabajo del profesor Valenzuela que, como de costumbre, toca varios aspectos de la dinámica económica y política de la región. Por supuesto, que aborda un conjunto de temas que son producto de un trabajo de muchos años, donde ha decantado un enfoque teórico marxista heterodoxo, con esto quiero decir que tiene la riqueza de tomar de forma crítica el trabajo de Marx, su esencia como método revolucionario, y nutrirlo de lo mejor del debate teórico-estratégico de las ciencias sociales críticas en América Latina.

Valenzuela ya es considerado como uno de los grandes exponentes del pensamiento latinoamericano, con influencias fuertes del viejo, pero siempre nuevo, estructuralismo latinoamericano. Se podrían rastrear en los trabajos del autor, lo mejor de Prebisch, Furtado, Anibal Pinto, Ahumada, Noyola, pero a su vez, combinado con el pensamiento marxista. Yo diría que la utilización de Marx que hace Valenzuela, no es en el sentido de un método abstracto sino como método concreto que se desarrolla, para lo que también integra a los grandes divulgadores del marxismo en

* Profesor del Centro Regional de Profesores del Centro y de la Universidad de la República, Uruguay.

Comentarios en la presentación del libro llevado a cabo en Acapulco, Guerrero; con motivo del Simposio Internacional 150 años de El capital de Carlos Marx, septiembre de 2017. 


\section{OSCAR MAÑÁN}

América Latina como Baran y Sweezy. Pero, por si esto fuera poco, es un gran lector de los grandes economistas burgueses, que distingue perfectamente al igual que Marx, de los economistas vulgares.

En qué radica la fuerza del trabajo de Valenzuela, porque sin duda es un intelectual orgánico del bloque popular en América Latina, es parte activa de la lucha de los pueblos latinoamericanos por la liberación; carga en sus espalda los logros y las frustraciones de la clase obrera y sectores populares, por esto sus libros logra una síntesis viva de lo mejor del pensamiento latinoamericano. Esto, de síntesis viva, implica que el autor siempre la pone a la consideración crítica, lo que más me ha gustado siempre de Valenzuela es que valora mucho el intercambio, los trabajos serios aunque no acuerden con él, siempre que tengan una argumentación fuerte. Esto lo hace un viejo, joven.

Por razones de tiempo me voy a dedicar a un aspecto muy parcial del libro que tiene que ver con las consideraciones respecto a la dimensión política que hace Pepe en su trabajo.

En especial hace un completo análisis, incluso como siempre aportando una metodología para describir primero y entender después la acumulación capitalista y los problemas del patrón de acumulación (en este caso a las experiencias de México y Estados Unidos), hoy muy articulados en sus aspectos económico-políticos. Ya es un clásico Valenzuela para entender este concepto de «Patrón de Acumulación», que además de sus determinantes objetivos que él describe muy bien y apunta el soporte empírico de prueba, también resalta la importancia de las condiciones subjetivas a la hora de adelantar el sentido del cambio social.

Identifica como uno de los grandes problemas del patrón de acumulación neoliberal, las insuficiencias de realización, es decir, las dificultades que tiene el neoliberalismo para absorber el potencial productivo, misma 
que lo que lo lleva a una muy magra dinámica económica. Esto refuerza la resistencia de la clase burguesa que para mantener sus ganancias sigue aumentando fuertemente la tasa de explotación por los mecanismos más retrógrados (bajando el valor de la fuerza de trabajo, vía disminución de salarios), lo que conlleva a su vez, problemas de distribución y pobreza conocidos. Pero además, ese crecimiento del excedente económico debido a una alta tasa de explotación («impropia» dice Valenzuela para las condiciones incluso de viabilidad económica del modelo) se combina con una muy baja inversión.

Para pensar alternativas de salida a este patrón neoliberal, primero conceptualiza las crisis cíclicas de aquellas de carácter estructural. La crisis del 2007-2008 evidenció una crisis cíclica que además tenía raíces estructurales; si bien apareció una restauración cíclica momentánea esta fue «perversa» en la medida que amplía las condiciones estructurales de la misma. Por lo tanto, la salida deberá ser de un reordenamiento del funcionamiento estructural de la economía, pero a su vez, también de las condiciones subjetivas que hace a la articulación de la dominación de clases y fracciones que le dan viabilidad política-ideológica al cambio social.

Sobre las salidas posibles a la crisis estructural de lo que llama Valenzuela «Patrón de Acumulación neoliberal», discutirá aquí tres alternativas posibles. La vía socialista que la ve poco «factible en el corto plazo», puede suponerse que dado el entorno de las luchas de clases y la poca capacidad actual de articulación del bloque popular en sus representaciones políticas de hoy día.

Otra que podría ver más probable, ya que implica montarse en las altas formas de explotación vigente, la que tipifica con rasgos de «nacionalismo fascistoide» ya que implica grandes dosis de autoritarismo político, gasto 


\section{OSCAR MAÑÁN}

militar y potenciación de la industria de guerra son algunas de sus condiciones subjetivas y objetivas que la contextualizan. Estados Unidos y algunos países europeos parecen dar pasos en este sentido.

Una vía «democrático-burguesa» que implicaría asimismo un aumento de la distribución del ingreso, quizás potenciando el desarrollo de los mercados internos y la industria de sustitución; que por la ruta de moderar la tasa de plusvalía (¿quizás con una mayor carga impositiva al capital, en especial al capital transnacionalizado sea nacional o extranjero?); con ello reduciría el excedente económico dado el ingreso nacional y por allí saltar las crisis de realización recurrente del patrón neoliberal.

Justamente, el trabajo de Valenzuela, sirve para reflexionar sobre la realidad de varios de los países de la región, si bien en este caso su estudio empírico refiere a las economías de México y Estados Unidos.

Los ejemplos, particularmente los del sur de América, quizás con algunas variantes en la dinámica estructural, pero es posible aplicar las dimensiones políticas del patrón neoliberal que expone Valenzuela. Veamos, Brasil, Argentina y Uruguay.

Estas experiencias mostraron por algún tiempo que el marco político del progresismo era el mejor para un desprestigiado patrón neoliberal que, como bien lo señala Valenzuela, se caracterizó por bajo dinamismo económico (en los 1990) retomó cierto dinamismo en los años pos-crisis del 1998-2002; hasta la crisis 2008 donde otra vez se modera el crecimiento.

Los avances se basarían en un marco más regulado de la relación capital-trabajo, donde se profundizaría la democracia bajo los preceptos de programas de mejora de las condiciones de vida de los sectores más necesitados (básicamente asistencialistas) y políticas que rescataban como avance de las políticas neoliberales la gestión macroeconómica (bajo 
déficit fiscal, baja inflación y un tipo de cambio competitivo, apertura al mundo, menores tasas impositivas para el capital, acuerdos comerciales amplios). Cierta mejora en la distribución en el caso de Brasil y Uruguay, de la mano de programas asistencialistas, de mejora de los sectores exportadores, pero con gran aumento del grado de monopolio en la economía. En Argentina en particular, la distribución mejoró basado igual que en los casos nombrados en los altos valores de los commodities, pero a diferencia de los anteriores con una intermediación del estado en la participación de la renta de los complejos exportadores (en especial la soja). Esto posibilitó al Estado a generar cierta protección de los mercados domésticos y dadas las condiciones de salida de la crisis de deuda (de espalda a los mercados internacionales) le posibilitó cierta industrialización protegida y financiada por la renta (retenida) de los sectores graneleros.

Esto funcionó básicamente hasta una nueva ofensiva de la clase capitalista que incluso forjaría la legalidad en Brasil para instalar un cambio de rumbo en el gobierno de decidido regreso al neoliberalismo. En particular, la reforma laboral que se abre camino en ese país impacta en toda la región, dada las características continentales de la economía brasileña y el cambio macroeconómico que implicaría en términos de competitividad. En Argentina, fue por la vía electoral que se implementó un cambio de gobierno, fuerte ajuste fiscal, regreso a la desregulación y apertura extrema, baja de las retenciones de impuestos y desprotección de la economía doméstica de la mano de sectores empresariales vinculados a la centro-derecha.

En Uruguay, particularmente, donde el capital está teniendo retornos importantes en la última década y media, hoy la burguesía aprovecha también el impulso de los cambios en Brasil para rediscutir la institucionalidad de negociación colectiva entre el trabajo y el capital. Durante el 
progresismo, se rescataron los consejos de salarios, como forma de regular la relación capital-trabajo y generar cierta estabilidad política. La paz sindical y la dinámica económica permitieron mejorar los ingresos en los sectores obreros más deprimidos, si bien la desaceleración posterior subordinó tales mejoras a los objetivos de política económica. Ahora, lisa y llanamente puede volver a ser la variable de ajuste para la competitividad regional amenazada por la caída de costos en Brasil.

Valenzuela y su trabajo invitan a pensar sobre las posibles salidas, y todos los que disfrutan su seminario, tienen una oportunidad invaluable para reflexionar sobre sus realidades, locales, regionales y nacionales; pero también su lugar en la construcción de un mundo mejor.

\section{Referencias}

Valenzuela, José C. (2017), De la crisis neoliberal al nacionalismo fascistoide, México, Universidad Autónoma Metropolitana. 